\section{EL PENSAMIENTO NORTEAMERICANO EN BILBAO (1948-1968). UNA VÍA HACIA LA MODERNIDAD ESPAÑOLA}

\author{
Luis Bilbao Larrondo \\ luis.bilbao.larrondo@gmail.com
}

\begin{abstract}
Cómo citar este artículo/Citation: Bilbao Larrondo, L. (2016). El pensamiento norteamericano en Bilbao (1948-1968). Una vía hacia la modernidad española. Arbor, 192 (781): a352. doi:
\end{abstract} http://dx.doi.org/10.3989/arbor.2016.781n5009

Recibido: 18 marzo 2015. Aceptado: 12 julio 2015.

RESUMEN: Al analizar la importancia de las bases americanas en España en la modernización del país durante el periodo franquista, también constaté que otros, por el contrario, le habían concedido una mayor trascendencia a los viajes de los técnicos, políticos, científicos e industriales a los EE.UU. En este estudio además de esas dos propuestas también hemos investigado la influencia que tuvieron en la culturización de los valores netamente norteamericanos, la prensa escrita, las revistas científicas y la Casa Americana (Bilbao). Aquel pensamiento suscitó además de un progreso científico y tecnológico extraordinario, un cambio en la mentalidad que hizo que fuesen determinantes en poder traer la modernidad norteamericana a ciudades como Bilbao.

PALABRAS CLAVE: Estados Unidos; Bilbao; modernidad; progreso científico; arquitectura; pensamiento.

\section{THE AMERICAN SCHOOL OF THOUGHT IN BILBAO (1948-1968). A PATH TO SPANISH MODERNITY}

Copyright: @ 2016 CSIC. Este es un artículo de acceso abierto distribuido bajo los términos de la licencia Creative Commons Attribution (CC BY) España 3.0.

ABSTRACT: When analyzing the impact of the American Military Bases in Spain on the modernisation of the country during Franco's dictatorship, I also found that other people considered the trips to the USA by politicians, technicians and scientists to have had a bigger impact. In this project, apart from these two trains of thought we have also analysed the influence that The American House in Bilbao, the scientific magazines and the press had on the spread of typically American values. This current of thought not only brought about extraordinary scientific and technological progress, but also enabled a change of mentality which proved to be decisive for the arrival of American modernity to cities like Bilbao.

KEYWORDS: Bilbao; modernity; scientific progress; architecture; thought. 
«El alma americana está hecha de y desde la soledad...»

(Julián Marías, Los Estados Unidos en escorzo).

"The main characteristics of American architecture are the simplicity, extensive use of colors and first-class materials such as wood, glass, aluminum, stainless steel, metal panels and boards....and the new ones like fiber glass, plastics and synthetic products. Because this is the steel country, steel construction is the most used and in wonderful manner; but I have also noticed extraordinary interesting samples of concrete structures, especially for thin surfaces...»

(Valentín Picatoste, Experiences and Observations Spanish Architect in USA: Comparative critics in architecture).

\section{INTRODUCCIÓN}

Aquellas personalidades de la vida española que pudieron viajar a los Estados Unidos a finales de los años 40 y a lo largo de los 50, - de toda índole y posición como Julián Marías, Díaz Plaja, Augusto Assía, Adolfo Echevarria, José Luis Barcelo, Torcuato Luca de Tena, Carlos Sentís, Rodrigo Royo, Santiago Nadal, Gregorio Marañón, Francisco Javier Sáenz de Oiza, Fernando Chueca Goitia, Rafael de la Hoz, Luis Vázquez de Castro, Valentín Picatoste, Eugenio Aguinaga o Félix Iñiguez de Onzoño... ${ }^{1}$-fueron también quienes a su regreso, seducidos por lo que habían visto, trajeron no pocos e innovadores ideales de lo que entonces consideraban una anhelada modernidad. ¿Fue acaso la respuesta natural frente a una visión sustentada en el folclorismo y en lo que denominó el profesor Sambricio como falso tradicionalismo que existía en la España de posguerra? Aquellas conocidas figuras de la sociedad española introdujeron algunas de esas innovadoras premisas a través de sus memorias, artículos y conferencias, -desde diferentes ámbitos: filosófico, periodístico, arquitectónico, económico...- cautivados por aquellas imágenes, por aquel modo de vida e incluso por sus ciudades. Posteriormente, como una manera expeditiva de adquirir dichas innovadoras premisas, creyeron ingenuamente que simplemente con reproducirlas las adquirirían, para, a continuación, tratar de implementarlas en la sociedad española. Como consecuencia más inmediata se plantearon la posibilidad de imitar en sus ciudades los símbolos que hicieron tan poderoso a Nueva York, -la denominada capital del mundo y símbolo de la economía mundial-, con sus rascacielos, con aquella potente imagen de su verticalidad triunfante y del éxito de sus conocidos progresos científico-tecnológicos. Hubo quienes al volver trataron de explicitar lo que consideraban, qué fue lo que más les sedujo y qué creyeron que personificaba aquel país para convertirse en todo un modelo a seguir desde España.
Hubo relevantes investigadores, como el filósofo Julián Marías, quien sustentó, -tras una serie de viajes a los Estados Unidos a principios de los años 50-, que cuando se hablaba de ese país, la mayoría de las veces se hacía desde la ignorancia e incomprensión. Para sostener, acto seguido, que, no obstante, quien no pudiese comprender la realidad de los Estados Unidos no podía entender el mundo en el que vivimos².

Cuando, durante esos años, incluso quienes estudiaron la obra de los escritores norteamericanos contemporáneos, imbuidos de una sorprendente modernidad, -autores tan conocidos como Faulkner, Lewis, Dreiser, Neil o Cadwel-, constataron que lo descrito por esos escritores poco o nada tenía que ver con lo que te encontrabas en ese país. Era evidente porque en esa literatura se trataba siempre de hallar lo excepcional, con lo que no hacían sino sostener una singularidad más, pero la cual era descrita como netamente norteamericana. Otros pensadores, como el propio maestro de Julián Marías, José Ortega y Gasset, habían llegado a sustentar la idea de, siempre con miedo de exagerar, que los EE.UU. era un pueblo primitivo camuflado por los últimos inventos. Una posición que le venía como herencia de Hegel. Pero para Marías, lo trascendente era la idea de que la ciencia norteamericana se justificaba a si misma porque proporcionaba una vida cotidiana tan cómoda y segura como una cuna. Para acto seguido describirla como una delicia de vida. Expuso, no obstante, que se trataba de una equivoca interpretación la de quienes desde España habían viajado con anterioridad a EE.UU., siendo ese ideal con el que volvían un espejo en el que querían verse reflejados. Por ejemplo con la imagen que percibían y que posteriormente describían, pero únicamente lo hacían sobre cuestiones pintorescas. Sin embargo, para Marías, dicha actitud era quedarse en la simple epidermis. Por lo que llegó a sostener que era preciso ir más allá de los grandes símbolos propiamente norteamericanos: los drive in, los rascacielos, las factorías, los barrios y los carteles de Coca-Cola...El propio Marías, empero, incidió como algo singular e importante, en la terminología propiamente norteamericana y que se repetía de manera reiterada en muchos de sus escritos: drug store, honor sistem, frigidaire, on schedule, square, common green, shopping center, shop world, shopper's world, bargain's basement, kichenettes, daffodils, melting pot, american way of living and thinking, dado que eran singularidades, de todo cuanto había visto y de aquello que más le había impactado. Marías, en todo momento, trató de ir más allá de lo meramente evidente, y se refirió a ese país como el de las soledades conjuntas, con enormes ciudades de hierro, de cemento y de análisis, a las que 
él veía preciso, frente a lo descriptivo y obnubilador, atender al gesto de las cosas, a su fisonomía, a su expresión y llegar a ejercer un verdadero esfuerzo analítico. Sustentado todo ello en, -porque existía entonces, según Marías-, un sentimiento de absoluta confianza en todo lo que hacía el norteamericano.

Marías también fue muy crítico con autores como Henry Steele y su obra "The American Mind" -a pesar de prologarle en su edición española y de reconocer su importancia-, por lo que él consideraba como simplistas pero muy extendidas creencias en el imaginario de muchos, tanto las propuestas como aquella visión -inheritance and environment- basada en la herencia y el medio, que, según Steele, eran las que producían el carácter netamente norteamericano: pero además del medio, estaba el sentido de espaciosidad, la invitación a la movilidad, la atmosfera de independencia además de la incitación a la empresa y al optimismo.

Pocos años después, en 1960, en el Ateneo de Madrid, sería el filósofo Frederick Wilhelmsen, quien al hablar ante aquel auditorio sobre el alma norteamericana sostuvo análogas ideas a las de Marías, dado que sustentó que los estadounidenses estaban dirigidos hacia el futuro -y no al pasado en busca de caducas gestas, estéticas gloriosas y monumentales, como era el caso español-, si bien estos estaban influenciados por la ética protestante y el mito de la frontera. De hecho, llegó a sostener que quien no fuera capaz de comprender la frontera no podía pretender entender el alma norteamericana. Para acto seguido aseverar que la revolución tecnológica era el instrumento destinado a realizar el sueño de los Estados Unidos, es decir, una sociedad dominada por técnicos, científicos, psicólogos y publicistas. Wilhelmsen sostuvo un pensamiento: que para conservar su poder, los Estados Unidos se apoyaban en un estado tecnológico, en el que los científicos e ingenieros, eran vitales para su economía porque revolucionaban constantemente aquella forma de vida.

Hubo otros intelectuales del momento, que reivindicaban las mismas ideas de Marías y cuyas reflexiones se publicaron en la revista Atlántico, -de la Casa Americana-, como Charles Von Doren, quien llegó a sostener que Norteamérica había significado siempre la búsqueda de algo nuevo. Al igual que escritores como William Faulkner, quien cuando aseveraba en una entrevista que simplemente concedía cierta fe al hombre contemporáneo norteamericano en su aptitud para salir vencedor de las circunstancias y para triunfar con su destino, describía, una vez más, la singularidad netamente norteamericana. Luis Rodrí- guez Aranda, en otro escrito, reivindicaba el espíritu del pragmatismo americano o José Fernandez, quien evidenció, el impacto de quien llegaba por primera vez a Nueva York y que a pesar de conocer su skyline por las fotografías o por los films, aun así quería más luminosidad para convencerse de que aquellas masas las habían construido los hombres, lo que le producía un sentimiento contradictorio de admiración por el ser humano y, a la vez, le permitía poder palpar su propia insignificancia. Otros autores vendieron como el ideal propiamente norteamericano, que la felicidad de un pueblo estaba ligada al auge economico y su destino estaba irrevocablemente asociado con el desarrollo y la utilización del conocimiento científico. Arthur Schlensinger, por su parte, llegó a sostener que el pensamiento norteamericano más vital había sido empírico, pragmático, cuya trascendencia hizo de los Estados Unidos que fuese un país caracterizado por la innovación y el experimento.

Detrás de esta serie de reflexiones sobre los Estados Unidos, tanto de aquellos que viajaron a aquel país como de aquellos otros que estudiaron su compleja realidad, me llevaron a cuestionarme, si detrás de aquellas ideas, hubo, además de un verdadero anhelo de progreso en la praxis, si también lo hubo en el pensamiento. Es decir, no solo lo hubo en ámbitos económicos, militares o culturales, que fueron en definitiva los que le llevaron a ser el país objeto de deseo que era, sino que sobre todo en dos aspectos, tanto el arquitectónico como el científico, que eran los temas que a mí particularmente más me interesaba analizar. Si considerásemos que fue de esta forma, la siguiente pregunta que me lleva a plantear es ¿supuso un paso más hacia la modernidad española en general y la bilbaína en particular? y si esta que fue además de anhelada, necesaria y porqué se tomó una determinada vía y en cambio porqué se desecharon las otras.

\section{EL DEBATE EN LA PRENSA ESCRITA}

Una serie de artículos que se fueron publicando por la prensa escrita española durante los años 1948 y 1949, describían, por un lado, el cada vez mayor acercamiento, tanto económico como militar, entre los Estados Unidos y la España de Franco. Pero, por otro lado, considero que aquel mito norteamericano empezó a ser instrumentalizado por estos medios y por las autoridades, como una posible salida para el futuro de un país que necesitaba, además de abrazar la modernidad como signo de progreso, pretendía ser a su vez la vía de supervivencia para el Régimen además de un revulsivo a su maltrecha economía. 
Aquella decidida pretensión de tratar de mimetizar aquellos conceptos americanos, en las ciudades españolas, que pretendían provocar no solo un cambio formal sino que también ideal, de ruptura con su pasado más inmediato, y alcanzar lo que sostenían debía de ser una nueva y moderna faceta urbana, podemos sostener que esta idea empezó a vislumbrarse a finales de los años 40. Todo ello tuvo inicio con una campaña desde varios medios de la prensa escrita con la publicación de unas series de artículos que describían los asombrosos progresos ocasionados en todos los ámbitos imaginables de los Estados Unidos. Las series editadas por diarios como Pueblo o Informaciones, se titularon: "España y el Plan Marshall", "Nueva York hoy", "Cosas de EE.UU.", "Descubrimiento de Norteamérica”, "La construcción en Estados Unidos" o "Nueva York vive así".

Pero este plan también producía otro tipo de reflexiones ¿̇era este tipo de campañas consecuencia de aquella decidida voluntad de las autoridades españolas por modernizar sus ciudades o fue por el contrario parte de la política de las autoridades estadounidenses por empezar a tratar de atraer a los sectores más influyentes de esta sociedad ganando propagandistas para su causa?

Fue el diario Pueblo, a través de su serie "Descubrimiento de Norteamérica" el que sustentó algunas de estas premisas por medio de una serie de heterogéneos personajes que habían estado ya en los EE.UU. para describir ante la sociedad española cual era su modo de vida; su arquitectura, infraestructuras, construcción, teatros, museos, ideología, shopping centers, barrios, hospitales, potencia militar, cine, cultura, Nueva York, economía, prensa...Serían otros diarios, como Informaciones, a través de su enviado especial, Adolfo Echevarria, quien, en sus artículos, describía cuestiones aún más cotidianas sobre la ciudad de Nueva York y sobre los Estados Unidos. Pero me crea cierta incertidumbre sostener que estos a su vez fueran conscientes de estar culturizando no solo con un léxico netamente norteamericano sino que también con una serie de importantes símbolos que representaban su riqueza y ostentación, -que era un más que directo método para cautivar a los españoles-, con aquellos lujosos y grandiosos automóviles de General Motors, Chevrolet, Pontiac, el Buick, el oldsmobile... Ni que decir tiene el efecto que tuvo en el imaginario de los lectores el visionar los espectaculares rascacielos de hormigón armado, acero y cristal, símbolos del progreso y de los avances en la arquitectura, tal y como sucedía con el barrio de Rockefeller Center, con su poderosa economía, con sus extraordinarios adelantos tecnológicos, con el singular urbanismo sostenido o con la monumental Quinta Avenida. (Fig. 1).
Figura 1. Garajes y parking
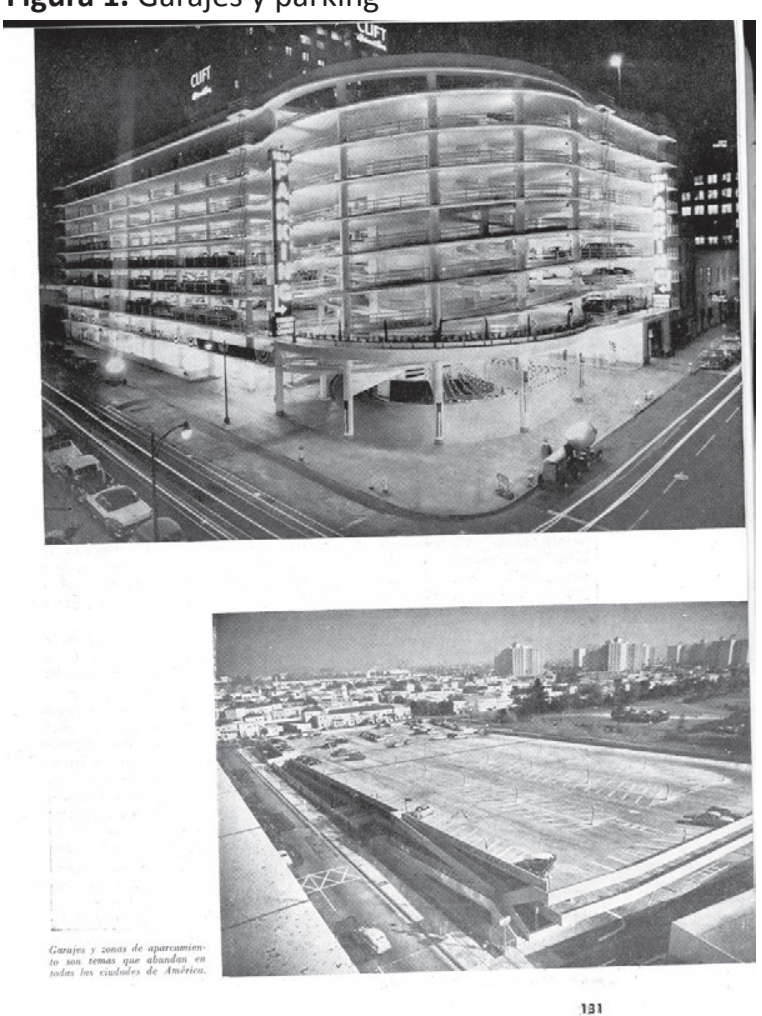

Fuente: Proyectos de viviendas y urbanismo de los Estados Unidos, Comisión Nacional de Productividad Industrial, Ministerio de Industria, 1959.

Las descripciones que se realizaron desde los diarios Pueblo, Arriba o Informaciones, sobre la ciudad de Nueva York, tenían su propia lógica dado que para los dirigentes y financieros e industriales españoles, esta metrópoli era sinónimo de éxito y modelo de ciudad del futuro. Fue tachada por los articulistas españoles como la ciudad de las ciudades, describiendo su modo de vida, su historia, su dominio económico mundial a través de Wall Street, sus construcciones de Manhattan, Brooklyn o Queens, sus espectaculares infraestructuras, con sus grandes avenidas, puentes y túneles. Quienes anhelaban desde la prensa española la modernidad norteamericana para España, proponían tratar de adquirir esta, si bien a través de heterogéneas facetas, pero que, no obstante, no tenían otra idea para apropiarse de ellas, que tratar de reproducirlas. Por ejemplo solo hay que recordar las palabras del profesor Sambricio sobre la cultura estadounidense de los hermanos Otamendi y de los financieros de sus proyectos del Banco de Vizcaya quienes tras sus frecuentes viajes a Chicago, Nueva York y Boston volvieron con una moderna imagen arquitectónica para el Madrid de posguerra. 
En otra de las series de artículos publicados sobre los EE.UU., estos fueron escritos por protagonistas de la vida social madrileña que viajaron a Nueva York, describiendo su siempre fascinante modus vivendi, sus grandes supermercados, de todo aquello que estaba construido para poder vivir desde el automóvil, como sus restaurantes automáticos. También resaltaban, como no, todos los más significativos rascacielos como representantes de su riqueza, de su altísimo nivel de vida, ya que eran auténticos monumentos al progreso. Entre sus grandes alardes constructivos describieron el Rockefeller Center, el Chrysler Building, el Empire State Building, el puente de Brooklyn, Central Park o los almacenes Macys. Detallaban en esos artículos sus asombrosos adelantos técnicos y científicos, ya que llegaron a sostener que los norteamericanos continuamente inventaban máquinas para sustituir el esfuerzo personal y así poder producir más. También destacaron como una faceta realmente seductora, el alma compleja como ciudad que tenía Nueva York, con su espíritu dinámico y práctico, descrito por la prensa española como la ciudad de las oportunidades, de las sorpresas, exuberante, la urbe de la esperanza, moderna y orgullosa de esa modernidad ${ }^{3}$. (Fig. 2)

Figura 2. National Housing Center

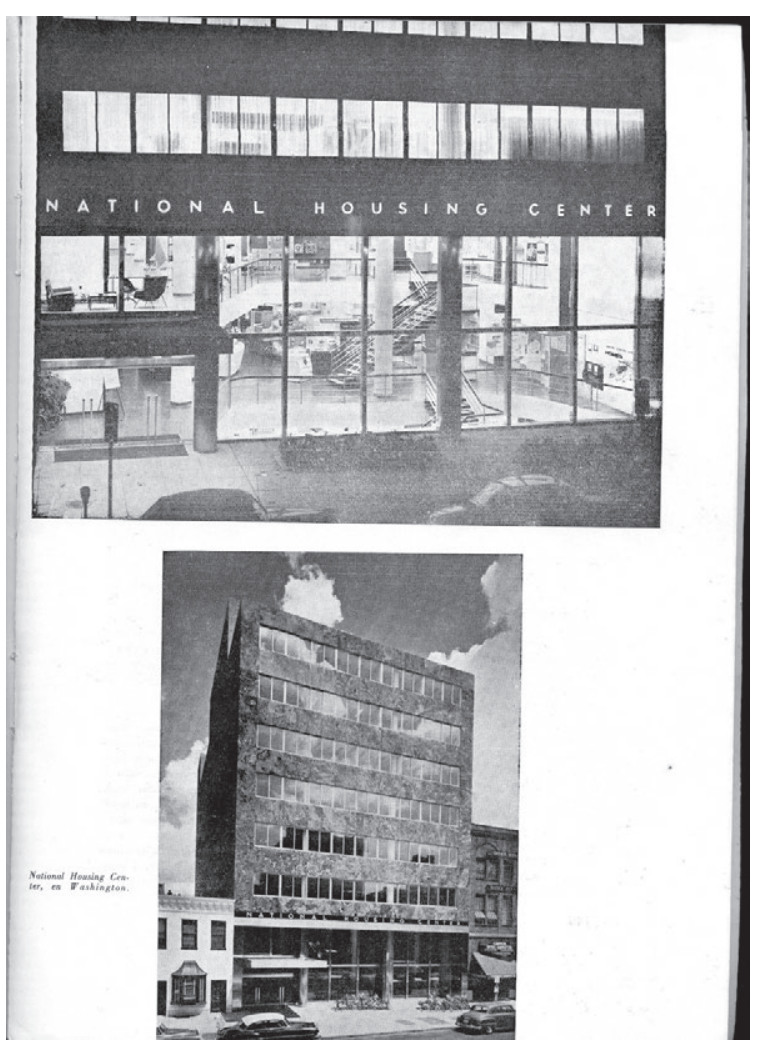

Fuente : Proyectos de viviendas y urbanismo de los Estados Unidos, Comisión Nacional de Productividad Industrial, Ministerio de Industria, 1959.
Fue el filósofo Julián Marías, sin embargo, quien hilvanó más fino al describir la gran manzana, ya que sostuvo que si bien Nueva York era América, América no era Nueva York, sino todo lo contrario. Se trataba de dos conceptos totalmente antagónicos, dado que de Nueva York destacó ante todo la prisa, frente a la calma americana; la inestabilidad y la sorpresa frente a un país hecho de cotidianeidad; el vértigo frente al tiempo a remansarse; la imprevisibilidad en la tierra, -que tiene un culto entre religioso y supersticioso-, frente a la previsión. Nueva York era una ciudad centrífuga. Nueva York, para Marías, era el pulso de Norteamérica.

La otra ciudad que más veces describió en sus artículos la prensa escrita -en Bilbao, sobre todo, por ser tomado como el modelo de ciudad que anhelaban sus dirigentes locales- fue Pittsburgh y tenía una evidente razón del porqué. Pittsburgh fue descrita en todo momento como la ciudad modelo fabril, del acero, la ciudad de los millonarios, suscitadora de un imaginario de la riqueza, fantástica, centro omnipotente de la industria carbonífera, de la industria del hierro, del petróleo, del gas natural, de las grandes industrias como la Westinghouse o la US. Steel, auténticos sinónimos de riqueza y modernidad. Retrataron en esos artículos las centenares de humeantes chimeneas, centenares de grandes fundiciones de acero, -centenares de industrias y gigantescos hornos que fundían miles de toneladas de acero que se convertirían en automóviles, frigoríficos, vigas, materiales de construcción o maquinaria, gracias a su extraordinario progreso científico y técnico-, que durante las noches ofrecían un efecto purpúreo al salir los grandes bloques de los altos hornos junto a las rojizas Ilamaradas. Recordaba esa estampa a los Altos Hornos de Vizcaya, de ahí que los norteamericanos denominaran a Bilbao como el Pittsburgh español ${ }^{4}$.

Tampoco nos puede resultar extraño, que en aquella realidad de posguerra, una España bajo un régimen dictatorial, sancionada y aislada internacionalmente por las Naciones Unidas, con una pobreza y hambruna generalizada en el ámbito rural, de grandes restricciones y de estraperlos, de cupones y de cartillas de racionamiento en las ciudades, las autoridades terminasen convirtiendo a los Estados Unidos y a sus urbes en todo un mito de la riqueza y de la modernidad, en todo un modelo de país y de ciudades a seguir. Y es que a través de la mimetización de todos esos símbolos se pretendía que dicha idea fuera adquiriendo una extraordinaria fuerza entre aquella empobrecida población que percibía y con- 
templaba, absolutamente cautivada y fascinada, todas aquellas noticias e imágenes sobre el modo de vida estadounidense y de sus ciudades, sin llegar muy bien a entender siquiera, que era aquello que les señalaban, qué era progreso y qué modernidad.

A los artículos en los que se traducían algunas de las publicaciones del New York Times o del New York Telegraph, les siguieron aquellos otros en los que se vendió su poderoso imaginario: "Americans are like that", el avión atómico, Manhattan, la fé y el optimismo de la vida americana y los salarios muy elevados que les permitían aquel frenético nivel de vida. Incluso la vivienda prototipo norteamericana propuesta en el año 1950, era descrita por la prensa escrita española como una vivienda automática, mecánica, que funcionaba mediante un ordenador, con células fotoeléctricas y micros en la puerta, con plásticos, aislantes y con lana de vidrio en las paredes. Esta vivienda venía a defender la necesidad de la investigación como único modo de progresar y a constatar como consecuencia de ello los prodigiosos progresos científico-tecnológicos promovidos. (Fig. 3)

Figura 3. Vivienda tipo en Estados Unidos

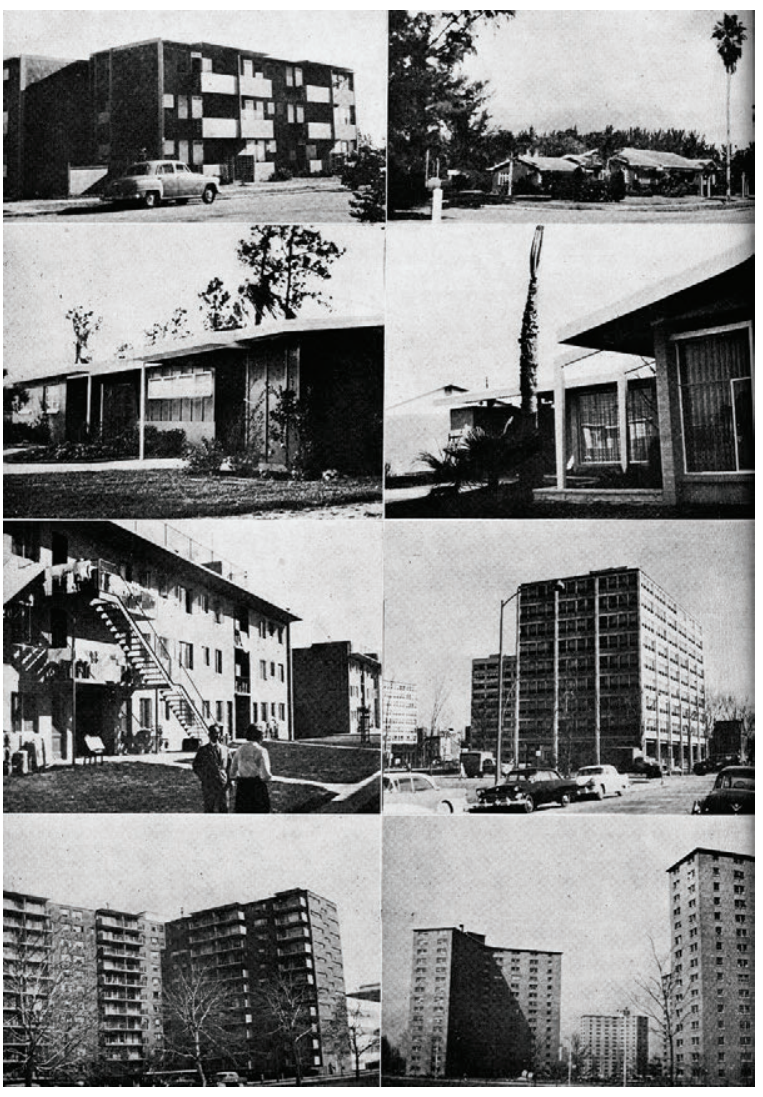

Fuente : Proyectos de viviendas y urbanismo de los Estados Unidos, Comisión Nacional de Productividad Industrial, Ministerio de Industria, 1959.
La influencia norteamericana fue aún mayor de lo que se ha supuesto, ya que articulistas del diario Pueblo, como Emilio Romero, defendían que las modificaciones que sufrían ciudades como Madrid, con las grandes edificaciones en forma de rascacielos y el cada vez mayor número de cafeterías americanas, sostenían un nuevo lenguaje de mayor altura, modernidad y velocidad vertiginosa en la vida urbana. Lo que hizo cambiar no solo la fisonomía más externa de Madrid sino también su fisonomía más íntima.

Pero no quedó ahí esa pretensión, porque ante el grave problema que sufrían las ciudades españolas, con el extraordinario déficit en viviendas que soportaban, el columnista Emilio Romero, contradiciendo a los máximos dirigentes del Instituto Nacional de la Vivienda o a los dirigentes de las promotoras privadas, propuso abordar los problemas con medidas más radicales, a través de la construcción de viviendas en serie basándose en la experiencia americana en prefabricación. Incluso se dedicaron desde el diario Pueblo monográficos en torno al arquitecto Frank Lloyd Wright, tachado, por, al menos parte de la prensa española, como el genio creador de la arquitectura orgánica, ensalzando esa arquitectura emblemática de Taliesing West y del Guggenheim de Nueva York.

Todo ello no hacía sino contradecir a los mismos dirigentes del gobierno como el Ministro de Trabajo, José Girón, quien en 1956 seguía defendiendo una arquitectura, propiamente española, sustentada en una vuelta al pasado -Herrera, Villanueva,...- y arremetía duramente contra la arquitectura moderna. Otros diarios como ABC o Arriba, retrataban Chicago o Nueva York a través de artículos de Iñigo Santiago, Andrés Revesz, Andrés Travesi o Luis Armiñan y coincidían en las mismas acepciones descriptivas sobre la seducción que ejercían este tipo de metrópolis en España.

Siguiendo esa misma línea de desarrollo, desde Bilbao, el diario El Correo Español/El Pueblo Vasco, empezó desde finales de los años 40 a editar varias series sobre los Estados Unidos a través de sus enviados especiales a Nueva York como Augusto Assia, Adolfo Echevarria o personajes de cierta relevancia como el director del Mundo Financiero José Luis Barceló, quien a su llegada a Nueva York, esperaba una moderna concepción de la vida en todos sus aspectos. En dichos artículos describía la fascinación que ejercía aquel país, con aquel American Way of Life, su afán creador, original e innovador. Aquel progreso científico tecnológico y su riqueza económica no eran según este diario sino producto de la audacia, del riesgo y de la standarización norteame- 
ricana. No obstante, también advertía de los riesgos para España de pretender reproducir aquellos sistemas en la arquitectura y una racionalización en el resto de facetas, al igual que ocurría en la vida americana. Augusto Assia y José Luis Barceló, desde ECE/EPV, también describían en sus artículos símbolos netamente norteamericanos como su sistema económico, industrial o de prensa. Además de otras cuestiones cotidianas como la productividad verdadera llave del bienestar o que el alto salario del que disfrutaban era el que permitía gozar a los americanos de los adelantos de la técnica moderna como los automóviles, la TV, el frigorífico o los chalets. Luis Hernández Franch, gran conocedor de aquel país, desde este mismo diario, escribía sobre los numerosos beneficios que producía para la sociedad The National Bureau of Standard, y sobre la importancia de la estandarización en la vida americana. Puesto que aconsejaba a los fabricantes que redujesen el número de tipos, tamaños, evitando la anarquía, produciendo en serie un número elevado de productos, como por ejemplo, las viviendas. No obstante, resultaba esta idea contradictoria sobre la valía de esta entidad, ya que la acusaban desde la prensa también de causar indiferenciación, uniformidad, similitud, igualdad, cantidad, inmensidad, gregarismo e incluso vulgaridad ${ }^{5}$. (Fig. 4).

Otro caso reseñable sería la fascinación que sentía Francisco Lucientes, quien desde ECE/EPV, escribió sobre el extraordinario poder norteamericano en todos los ámbitos, algo, por otro lado, totalmente comprensible por la fuerza que había ido adquiriendo esta idea en el imaginario español. Hubo quienes no podían llegar a entender que, con aquel anhelo de ruptura con lo anterior, de cambio, a través de una innovadora simbología

Figura 4. Proyecto de centro comercial en Estados Unidos

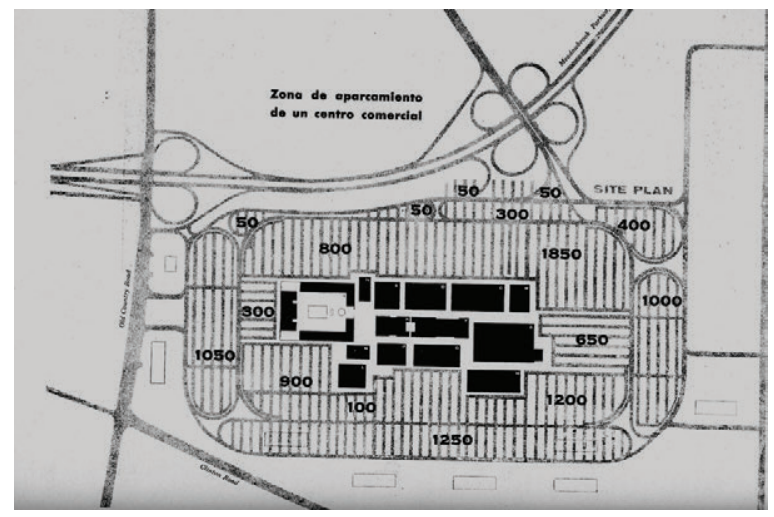

Fuente : Proyectos de viviendas y urbanismo de los Estados Unidos, Comisión Nacional de Productividad Industrial, Ministerio de Industria, 1959. e iconografía, ese paso les llevaría a una nueva escenografía, que, a su vez, también estaba originando una metamorfosis en el pensamiento. A partir de entonces, muchos ya no querrían seguir bajo aquel absolutismo de las formas rígidas, de las paletas cromáticas oscuras, de la estética arcaica ni de aquella visión retrograda, exigidos por el gobierno. Todo aquel innovador léxico trajo consigo algo más que anhelos de libertad cultural.

\section{LAS REVISTAS Y SUS DISPUTAS CIENTÍFICAS}

Desde las revistas científicas locales, hubo un evidente posicionamiento, en torno a lo beneficioso para ciudades como Bilbao, el tratar de reproducir las políticas científicas de los Estados Unidos. Se proporcionaban cifras de inversiones y de éxitos, sobre cuál era el camino a seguir, dado que en 1952, los Estados Unidos habían destinado más de tres mil millones de dólares en investigación y tenían en plantilla más de ciento cuarenta mil científicos. Llegó a ser descrito por estas publicaciones de ser el país modelo a seguir dado que preparaba las revolucionarias técnicas del mañana a través de la investigación en todos los ámbitos imaginables.

Por otra parte, hubo un importante cambio en las aportaciones de los arquitectos españoles, como fue el caso de Luis Moya -el mismo Moya del Sueño Arquitectónico a la Exaltación Nacional-, quien tras su viaje a los Estados Unidos escribió varios artículos en la Revista Nacional de Arquitectura, en los que constató, entre otras cuestiones, la brillantez de los edificios de Frank Lloyd Wright y la influencia no solo de su arquitectura sino que también de su ideología y de sus slogans en los arquitectos americanos. También sostuvo sobre Wright que este llegó a proponer a los jóvenes arquitectos que fueran donde pudieran ver las máquinas y los métodos de trabajo con los que se creaba la casa moderna. Moya sostendría posteriormente sobre la modernidad en la arquitectura estadounidense, la influencia que llegaron a ejercer las revistas técnicas gracias a las cuales se aplicaban los recursos de la técnica industrial e inventiva formando viviendas modernas.

Poco después fue el profesor Fernando Chueca Goitia, quien, en sus publicaciones en la RNA sobre sus experiencias arquitectónicas tras un viaje a Norteamérica a principios de los años 50 , llegó a sostener que todo edificio importante que se realizaba en ese momento en aquel país se hacía en el estilo más moderno. Para acto seguido sustentar que una arquitectura moderna era aquella en la que destacaba el volumen geométrico en lugar de la masa de naturaleza escultórica, la que organizaba el espacio 
con sentido dinámico por medio de planos conjugados. La arquitectura moderna para Chueca Goitia era aquella que se basaba en la expresividad de la estructura y en la flexibilidad de planta no condicionada por la simetría axial. La arquitectura moderna, era aquella que se afirmaba por medio de las proporciones, la calidad de los materiales y la textura de las superficies en lugar del ornamento aplicado. Si bien la modernidad europea había ejercido su influencia en los EE.UU., según se desprendía de las ideas del Chueca Goitia arquitecto y erudito, parecía que todo quedase supeditado a partir de entonces a lo que planteasen los americanos.

Entretanto, se producía otro importante debate en las revistas españolas de arquitectura: en las cuales se cuestionaban cómo debían de avanzar arquitectónicamente. La disyuntiva que se suscitaba entre los arquitectos españoles era investigar desde dentro o importar de fuera aquella arquitectura moderna. El problema de la novedad de lo de fuera, era, que a pesar de que tenía buena venta, se hacía sin cribarlo ni meditarlo, ni las formas, ni las maneras, ni los materiales, todo se admitía, tal y como venía. Por ejemplo, todo lo que llegaba de los Estados Unidos por el hecho de venir de aquel país se reproducía por su simbología moderna. Hubo también quienes extendieron la idea de que frente a la precariedad española estaba el milagro de la modernización norteamericana, gracias a los catálogos de productos standarizados nacidos de una voluntad científica, con aquella imagen de modernidad que traía consigo una nueva estética de progreso y de confort ${ }^{6}$. Otros, en cambio, desde sus estudios sostuvieron la extraordinaria influencia que tuvieron en los arquitectos españoles sus viajes a los Estados Unidos y a su vuelta cómo trajeron nuevos criterios imbuidos de una supuesta modernidad, tal y como fue la idea de pretender manhattanizar nuestras ciudades ${ }^{7}$.

No podemos tampoco pasar por alto la apenas cuantificada labor de puente que realizó, entre Estados Unidos y España, la revista Informes de la Construcción del Instituto Técnico de la Construcción, cuyas premisas, a lo largo, sobre todo, de los años 50 , fueron fundamentales, ya que abogaban por reproducir las políticas científicas norteamericanas, si es que se quería lograr un progreso tecnológico en ámbitos tan necesarios como el de la construcción, para resolver, entre otros graves problemas, el de la vivienda. Defendían sus miembros un cambio de mentalidad que llevara a la intensificación de los rendimientos, taylorizando operaciones, que eran con- ceptos inusuales e incluso desconocidos en aquella España de la autarquía. Sostuvieron estos científicos el ideal de que el investigador necesitaba de la creación de modernos laboratorios, con materiales y aparatos innovadores, a través de técnicas depuradas, como en los Estados Unidos. España, basándose en el modelo científico de aquel país, debería de llegar a poseer las mejores condiciones de acelerar al máximo los progresos técnicos como signo de modernidad y para ello pretendían que se promoviesen verdaderas organizaciones investigadoras. Al parecer, los innovadores cimientos del futuro tecnológico español, en ámbitos como el de la vivienda y el de la construcción, estaban siendo fijados ${ }^{8}$.

\section{BASES AMERICANAS EN ESPAÑA Y LOS VIAJES DE LOS TÉCNICOS Y CIENTÍFICOS ESPAÑOLES A LOS ES- TADOS UNIDOS}

En una entrevista a Carlos Pfeifer, arquitecto que participó en el proyecto de las bases americanas en España, sostuvo que la arquitectura moderna hizo eclosión en España de manos de los americanos: en la Oficina Americana de Proyectos, la maquina taylorista de la estructura productiva americana se instalaba en España y el cambio que se produciría sería total. De ahí surgieron colaboraciones entre técnicos, se diseñaban y optimizaban detalles constructivos, se estudiaban y experimentaban nuevas patentes, la industrialización se hacía sinónimo de modernización y la sociedad española se hacía made in USA.

A Pfeifer no le faltaban razones para aseverar dichos axiomas, que el profesor Sambricio también los corroboraba, cuando unía en uno de sus brillantes trabajos de investigación, la abundancia y la riqueza de los economatos de las bases, los grandes coches americanos, las guías de soluciones standars, las viviendas para oficiales y otros edificios, como signos de la modernidad estadounidense. La propia arquitecta, Blanca Lleo, llegó a sostener, sobre el viaje de Sáenz de Oiza a los EE.UU., que como signo de modernidad este estaba más interesado por las nuevas tecnologías modernas que por el arte, ya que se dio cuenta de lo inventivo del espíritu americano, dado que la oficina de patentes era más importante allí que el museo del Prado en Madrid. El también arquitecto, García Millán, llegó a analizar los proyectos de las bases y las viviendas del Encinar de los Reyes, de la Moraleja y de Zaragoza, diseñados por los arquitectos Luis Laorga y José López Zenón, los cuales se dejaron seducir por el moderno modo de vida americano adoptando sus formas arquitectónicas. (Fig. 5). 
Figura 5. Viviendas bases americanas

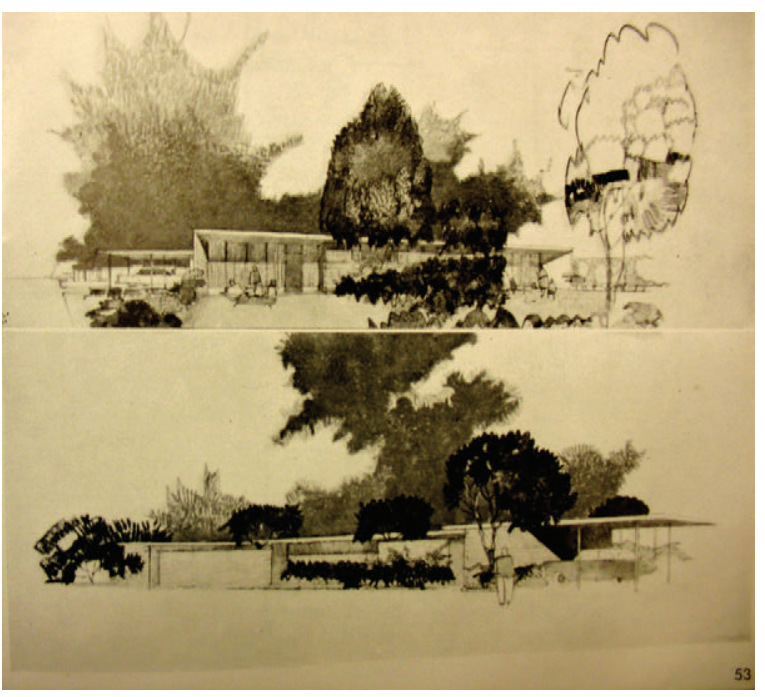

Fuente: Richard Neutra. Arquitectura, 85, 1965.

En otra serie de entrevistas que realicé a los también arquitectos madrileños Luis Vázquez de Castro o Valentín Picatoste, que igualmente trabajaron en la oficina de sitte planning de las bases o que pudieron viajar, con la Comisión Nacional de Productividad Industrial o con la beca Eisenhower a los Estados Unidos, estos llegaron a sostener que gracias a ese contacto pudieron manejar conceptos innovadores, nuevos aspectos cargados de modernidad, como la aplicación rigurosa de los american standard, que incluso les vino muy bien para posteriormente ganar varios concursos. En todo ello, algo tuvo que ver el que participasen en los proyectos de las bases dos primeras figuras de la arquitectura estadounidense: en primer lugar, Frederic Langhorst ${ }^{9}$, quien fuera discípulo de Frank Lloyd Wright y que estaba al frente de las Architects Enginers Spanish Basiers, junto a su mujer, la sobresaliente arquitecta y pintora Lois Langhorst.

En segundo lugar, el arquitecto de origen suizo, al frente de la oficina de anteproyectos, Jacques Seltz, discípulo de Mies van der Rohe, que trabajó tanto en Chicago como en Nueva York, y que pertenecía a la prestigiosa firma de Los Angeles, Pereira y Luckmann. La modernidad llegó no solo con el contacto con estos brillantes arquitectos y técnicos -como William Schoenfeld o Robert Swanson de Los Angeles-, sino que también a través de otras conocidas firmas como Skidmore Owings y Merrill de Nueva York o Shaw Metz y Dolio de Chicago.

Hubo un patrón argumental que se siguió en los viajes a los Estados Unidos, ya que quienes estudiaron la arquitectura, el urbanismo y la construcción lo hicie- ron siempre en torno a los mismos problemas que se padecían en España con idea de tratar de resolverlos implementando aquellas modernas soluciones. Estos viajeros se entrevistaron con los arquitectos más prestigiosos del momento de los Estados Unidos, Frank Lloyd Wright, Mies van der Rohe, Walter Gropius, Ludwig Hillberseimer, Eero Saarinen, Pietro Bellusqui, Louis Kahn, Jose Luis Sert...teniendo en cuenta que eran arquitectos europeos exiliados en su mayoría, pero que, no obstante, sería preciso destacar como los modernos arquitectos españoles que se exiliaron lo hicieron en su mayoría hacía países de América Latina.

Las visitas a las celebridades de la arquitectura estadounidense se llevaban a cabo por los arquitectos españoles como si de un asunto sacro se tratase, como el de los peregrinos que visitaban los lugares santos, fascinados los arquitectos españoles por las presencias y las obras de los que consideraban genios de la arquitectura, ya que se trataba de un soplo de aire de modernidad frente a la otra arquitectura ambigua que se hacía en España. A la vuelta de sus viajes, estos mismos arquitectos, daban conferencias de sus experiencias y opiniones sobre lo estudiado en EE.UU., ofrecían cursos monográficos sobre materiales innovadores que causaron una profunda admiración por aquella arquitectura de los centros comerciales, la planificación, las universidades, los centros culturales o bien escribían artículos y libros en torno a lo allí estudiado. La mayoría de ellos, a su vuelta se unían a la Asociación Cultural Hispano Norteamericana por identificarse plenamente con los valores norteamericanos. Produjo entre los que volvieron no solo un interés por la multidisciplinariedad sino que también una nueva estética material y espiritual, ya que se trataba de una arquitectura con una influencia global, la del país del acero, de la industria, de la construcción y de la abundancia. Entre los que volvieron se plantearon, así mismo, una nueva doctrina: desde entonces admirarían el orden americano frente al desorden español, lo heterogéneo frente a lo homogéneo, lo generoso frente a lo vanidoso. El verdadero cambio no vendría únicamente con la mimetización de los innovadores materiales o sistemas sino en cómo suscitar una metamorfosis intelectual. (Fig. 6).

Entre otras propuestas, se asumió, por parte de quienes regresaron de EE.UU., un léxico innovador y propiamente norteamericano con idea de poder ser aplicado en España: efficiency, ingenuity, simplicity, coverage...es decir, simplicidad en la arquitectura, eficiencia constructiva, iniciativa propia como base de la eficacia, además de libre competición y cobertura 
Figura 6. Arquitectos e ingenieros

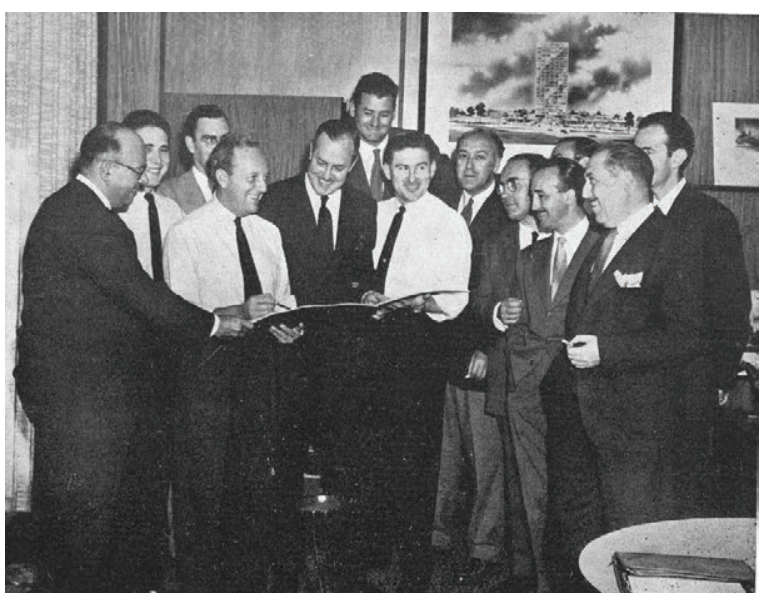

Fuente : Proyectos de viviendas y urbanismo de los Estados Unidos, Comisión Nacional de Productividad Industrial, Ministerio de Industria, 1959.

del terreno. Los técnicos españoles asimilaron en los Estados Unidos que una arquitectura moderna, se trataba de algo más que un arte creador personal, dado que era incluso más que el producto de una época, de una civilización y de un país. Constataron al estudiar aquellos grandes edificios comerciales, cómo estos se proyectaban, basando el valor publicitario en una exhibición arquitectónica, o al analizar los rascacielos, con aquella verticalidad triunfante, les llevó a comprender que la norma para la construcción de los rascacielos más modernos era la Lever House de Skidmore, Owings y Merril, construido gracias a los mayores avances tecnológicos. Arquitectos como Eugenio Aguinaga, al volver de los EE.UU., sustentaron que el valor principal de aquel país era la eficiencia por encima del gigantismo, de la prefabricación y de las técnicas. Virtudes todas ellas, que, según sostuvo Aguinaga, debían de conformar a una sociedad moderna a través a su vez del consumo, del progreso, del confort y de la innovación. (Fig. 7).

\section{CULTURIZACIÓN A TRAVÉS DE LA CASA AMERICANA -BILBAO}

El mayor instrumento culturizador -progreso y modernidad- de los valores norteamericanos que operó sobre las más importantes ciudades españolas, -también lo hizo sobre Bilbao-, fue la Casa Americana. Funcionó en Bilbao, desde el mes de Enero de 1949, mes en el que inició sus actividades, hasta el mes de Diciembre de 1961, mes en el que cesarían dichas actividades. Estuvo situada en la calle Buenos Aires número 1. La Casa Americana dependió en todo momento de
Figura 7. Lever House de Skidmore, Owings y Merrill

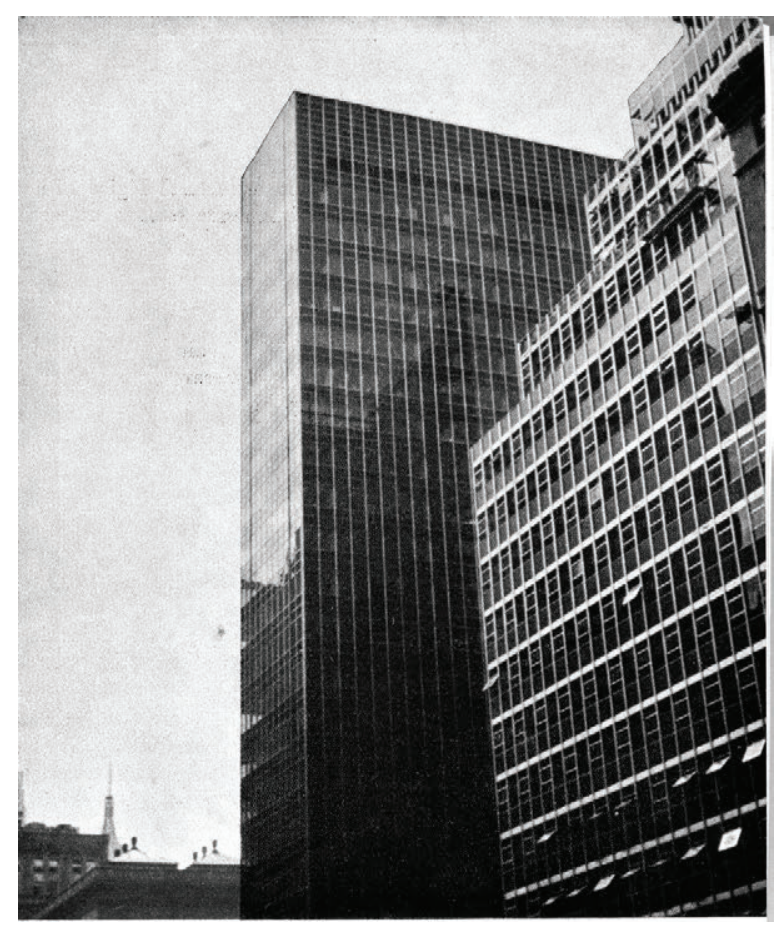

Fuente : Proyectos de viviendas y urbanismo de los Estados Unidos, Comisión Nacional de Productividad Industrial, Ministerio de Industria, 1959.

la embajada estadounidense, pero su gestión la llevaba el Instituto de Estudios norteamericanos, a la que pertenecía, al igual que la delegación Norte de la Asociación Cultural Hispano-Norteamericana, sociedad que se constituiría en Bilbao el 8 de Mayo de 1960, con 160 socios. La Asociación Cultural Hispano Norteamericana estuvo ubicada en la calle Alameda Recalde y al frente como presidente actuó el Catedrático en Ciencias Económicas, Fernando de la Fuente, y como vicepresidente, el arquitecto Eugenio Aguinaga.

Las actividades que promovió esta Casa Americana fueron tan prolíficas como heterogéneas. Desde las conferencias que tuvieron lugar tanto en el salón Washington Irving de la Casa Americana como en la Biblioteca Municipal sobre la relación de Bilbao con los Estados Unidos, hasta las políticas de la delegación de la Cámara de Comercio Americana en Bilbao. A ello hemos de adjuntar las conferencias que se promovieron sobre la organización y dirección de las empresas norteamericanas, las exposiciones sobre la prensa estadounidense o la Exposición del Átomo para la Paz en la Escuela de Ingenieros Industriales de Bilbao. En esta exposición, por ejemplo, divulgaron las ventajas de la energía atómica en la producción de energía 
para la industria bilbaína, con cursos de ingeniería nuclear y la cesión de la biblioteca de la Casa Americana, de bibliografía y documentales sobre la energía nuclear. También enviaron alumnos de la escuela de ingenieros a los Estados Unidos a estudiar en sus centros especializados, a través de la Foreing Operation Administration.

Dentro de aquella culturización, durante años, la Casa Americana de Bilbao llegó a posibilitar que pudieran acceder a numerosas becas para estudiar en los Estados Unidos, tanto a universitarios como a estudiantes de bachiller bilbaínos. Incluso llegaron a garantizar la posibilidad de cursar seminarios en el Instituto de Educación Internacional de Nueva York, el MIT o Harvard. También Ilegaron a promover el American Field Service de intercambio de estudiantes o poder acceder a las becas Fullbright a partir del año 1960. Tal y como sostuvo el embajador Lincoln Mc Veagh sobre la labor de las Casas Americanas en aquellos años 50 "sirven para hacer comprender lo que son los Estados Unidos, nuestra civilización, nuestras ideas y nuestra tecnología".

El que también fuera embajador norteamericano en España, John D. Lodge, estando de visita en Bilbao, sostuvo que era muy conocida la faceta industrial y económica de Bilbao para los estadounidenses y las estrechas relaciones que mantenían con los políticos bilbaínos el caso de Lequerica, Areilza, Iturmendi o Castiella- a los que describía como auténticos defensores de los valores norteamericanos. Theodore C. Streibert, Director de la United States Information Agency, que era el organismo oficial que regulaba los programas informativos y culturales, fue quien destacó la labor de las Casas Americanas y lo importante que resultaban aquellos intercambios de tipo cultural y económico.

Los acuerdos económicos promovidos por los norteamericanos en Bilbao, los conocemos a través de Milton Barall, Director de la Misión Económica de los Estados Unidos, quien confirmó en Bilbao no solo la inversión que harían en la fábrica de laminación de bandas en frio tanto para Altos Hornos de Vizcaya como para Basconia en Echevarri, con una ayuda inicial de mil doscientos millones sino que también se tuvieron en cuenta las más modernas técnicas americanas y la maquinaria principal que fue adquirida en los Estados Unidos dentro del programa de la International Cooperation Administration. Los trenes, los equipos de proceso y motores, por ejemplo, fueron suministrados por la International General Electric. Llegaron a invertir estos financieros americanos unos tres millones setecientos cincuenta mil dólares en proyectos como el de la central térmica de Burceña. Las misiones comercia- les prosiguieron con la llegada a Bilbao de un grupo de financieros americanos, -William L. Bech, Fisburgh Granger, Clarence J. Ruetling-, con el fin de contactar y negociar con la industria y la banca bilbaína.

La Casa Americana tuvo otra faceta de enorme trascendencia para Bilbao, y fue, según publicó el New York Times, la de ser un haz de luz frente a la oscuridad de la prensa española. Una Casa Americana que la podemos tachar de haber sido un canto a la libertad, frente al régimen y a los periodistas españoles. Porque hemos de rememorar la censura que entonces no permitía entrar noticias ni revistas ni diarios críticos con el gobierno. Los periódicos españoles, únicamente daban noticias positivas en torno a la España de Franco. En la Casa Americana, en cambio, los bilbaínos podían leer periódicos y revistas internacionales sobre aquella realidad incluso con noticias críticas con el Régimen.

Baste recordar la faceta de la Casa Americana en Bilbao como propagandista de la modernidad estadounidense, tras las impresiones de conferenciantes como los arquitectos bilbaínos que viajaron a los Estados Unidos como Félix Iñiguez de Onzoño y asistido por el vicepresidente de la Asociación Cultural Hispano Norteamericana, el también arquitecto Eugenio Aguinaga. Aquellos innovadores, pero ya conocidos conceptos que trajo Iñiguez de Onzoño, de trabajo, panorama urbano y características comunes en las ciudades norteamericanas, aquel contacto que tuvo con las masas de los rascacielos, con los aspectos plásticos, con las Ciudades Campamento del Oeste y la construcción, en poco o en nada había variado de aquellas que propuso cuando volvió Eugenio Aguinaga de los EE.UU. en 1957. Fue usual que desde 1956 los técnicos e industriales bilbaínos pudieran acceder a estos viajes a los Estados Unidos.

Al tratar, tanto de cuantificar como de cualificar estos hechos, constatas que estos centros realizaron una valiosa labor como instrumentos culturizadores de lo americano sobre ciudades como Bilbao, favorecidas desde la United States International Agency y la International Cooperation Administration, a través del fomento de relaciones culturales, científicas, económicas y artísticas, promoviendo el intercambio de profesores y alumnos, el envío de becarios, el patrocinio de actos culturales, de exposiciones y de conferencias sobre ciencias tecnológicas, arquitectura, pintura, fotografía y literatura norteamericana. Así como también se dedicaron a la distribución y publicación de folletos, exhibiendo documentales, promoviendo su sistema educativo, a través de las emisiones radiofónicas, la distribución bibliográfica a través de sus biblio- 
tecas, -y es que Bilbao llegó a tener más de cinco mil socios y más de diez mil lectores al mes-, con sus salas de lectura de prensa, programas de conferencias, de reuniones y de clases de inglés. Todo ello contribuyó a que la cultura popular, -en la que incluyo la arquitectura, el urbanismo, la construcción y las nuevas tecnologías-, es decir, algunos de las principales premisas del American Way of Life, llegaran no solo a instalarse en el imaginario de muchos bilbaínos y a transformar aquella realidad sino también a ser motivo de cambio en su forma de pensar en torno a la ciudad.

\section{EL SUEÑO DE UN NUEVO BILBAO}

Tal y como hemos podido constatar, si hubo una ciudad que abrazó ostensiblemente los ideales norteamericanos en los años 50 y 60, esa fue Bilbao. Empero, sería preciso recordar cómo el capital bilbaíno, presente en Madrid a través del Banco de Vizcaya y del Banco de Bilbao, llegó a tratar de reproducir sobre la capital, incluso antes que proyectos como el triángulo Princesa o AZCA, una evidente Manhatanización de Madrid, con el proyecto de una Gran Via Diagonal entre la Plaza de España y la Plaza de Colón. Dicho proyecto pretendía una réplica de las calles 42 y 55, -entre Madison y Broadway-, entre Callao y la Plaza España, con varios rascacielos y salas de espectáculos y una serie de comercios de lujo como los que había entre las calles 47 y 59 de Manhattan. Lo que originó un encendido debate entre el cineasta, guionista, escritor y diplomático, Edgar Neville, que era favorable a americanizar la capital por sus muchos beneficios más bien económicos pero también urbanos, y el arquitecto Miguel Fisac, que era contrario a dicha idea, puesto que no veía en esa supuesta americanización sino un aspecto meramente especulativo y perjudicial para la ciudad.

Por otra parte, los viajes realizados en los años 50 por periodistas, técnicos o políticos vizcaínos, como el alcalde de Gernika a la Feria Industrial de Atlantic City, las estancias de los embajadores en los Estados Unidos, José Félix Lequerica y José María Areilza, los viajes de los arquitectos Eugenio Aguinaga y Félix Iñiguez de Onzoño o la del escritor bilbaíno Esteban Calle Iturrino, el cual realizó un ejercicio descriptivo de su viaje por los Estados Unidos, tuvieron esa faceta de ser poco más que relatores de las grandezas de ese país, de su escenografía, de su modo de vida, pero sin llevar a cabo un profundo análisis, tal y como llegó a proponer Julián Marías. Al final, terminaron como otros, tomando como enseñanza lo que si se pudiera adaptar de aquella realidad a la de Bilbao como forma de lograr una más que anhelada modernidad.
Hubo también una insólita ambición por parte de la gran burguesía bilbaína; frente a Madrid, capital administrativa y espiritual surgida tras la guerra civil, pretendieron hacer de Bilbao no solo la gran metrópoli del Norte sino que fuera a su vez la capital industrial y financiera de aquella España. Reproduciendo para ello toda esa simbología norteamericana con el fin de poder adquirir aquel nuevo status no solo urbano a través de una innovadora iconografía sino que también de tipo económico. También sirvió como instrumento para tratar de romper con la imagen de un pasado y un presente que poco o nada tenían que ver con sus ambiciones, sobre todo, de tipo económico e industrial. Al pretender ser adaptado tuvo otras consecuencias porque que se conocieran sus proyectos constructivos e intentar su potencial reproductibilidad no quiere decir que quienes lo pretendieron comprendiesen las teorías y fundamentos principales de los autores para lograr dicho anhelo. No nos puede resultar del todo extraño, porque todas estas premisas fueron vendidas desde la prensa y desde otros medios, como virtudes o méritos que según sostenían debían de conformar el paradigma de ciudad que anhelaban los políticos e industriales bilbaínos, a través de una escenografía de la riqueza y como no, de lo que consideraban era la modernidad. (Fig. 8).

Figura 8. Banco de Vizcaya

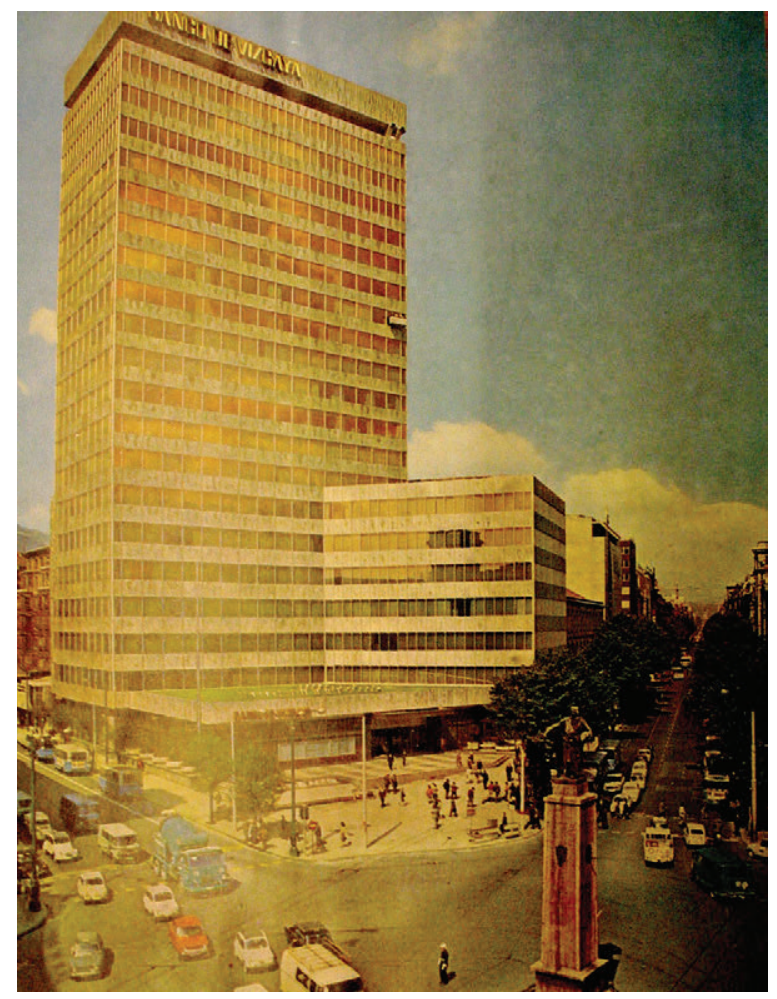

Fuente: Archivo Municipal de Bilbao. 
Estos propósitos tuvieron un apoyo total por parte de los políticos y empresarios bilbaínos, de ahí que más de la mitad de las inversiones del capital norteamericano en España, -a principios de los años 60fueron a parar a Bilbao. Los bancos bilbaínos se unían con los bancos norteamericanos en busca de negocios conjuntos. Se reprodujeron por las autoridades proyectos de ingeniería para infraestructuras -como el ferrocarril aéreo Telesirga Pagasarri basado en un proyecto norteamericano- no solo como solución a problemas urbanos sino que también con idea de recrear aquellos símbolos constructivos, con los que se trató de reproducir aquel modo de vida, sus ciudades, llegando a imitar sus edificios, rascacielos y shoppings centers, tal y como pretendieron hacer en Deusto -Plaza Pio X- o en Zabalburu -torres de Zabalburu-. Se utilizaron en estos edificios varios sistemas constructivos de prefabricación con patente norteamericana como señal de modernidad. La Cámara de Comercio, Industria y Navegación de Bilbao, consciente del significado de su éxito, estipuló que en el futuro desarrollo de la villa se tomara, como modelo de desarrollo, Manhattan, por su moderna simbología. Se erigieron rascacielos de oficinas para el Banco de Vizcaya, en el Ensanche de Bilbao, a imitación de los de Nueva York o se trató de reproducir sobre la trama urbana bilbaína la exitosa política urbana de Pittsburgh, Filadelfia o Nueva Orleans. También se llegaron a reproducir clubs de ocio y encuentro social, imitando las premisas arquitectónicas de Frank Lloyd Wright, para mayor delectación de la elite financiera e industrial bilbaína. También se llegaron a diseñar proyectos de ingeniería basados en varios proyectos americanos; un puente entre las Arenas y Portugalete, basado en el Cobo Hall de Michigan; se plantearon vías de comunicación fundamentadas en la autopista Lodge; se bosquejaron proyectos de túnel bajo la ría del Nervión entre Sestao y Lamiako, sustentados en el Holland Tunel; se proyectó una autopista basada en el New York Thruway e incluso se planteó reproducir el proyecto del plan Bertrand Goldberg de Chicago, en Bilbao. (Fig. 9)

Todas estas propuestas y pretensiones, sin embargo, llevaron a una realidad -a finales de los años 60-, que poco o nada tenía que ver con lo pretendido inicialmente por los dirigentes y técnicos locales sobre Bilbao: la mera reproducción al conllevar una falta absoluta de criterios científicos, no era una solución a largo plazo ni la más óptima para resolver los problemas de Bilbao ni para lograr la anhelada modernidad. A ello se unía la falta de ambición cultural de dicha política porque en ningún momento llegaron a entender qué había detrás de esos supuestos. También ocasionó
Figura 9. Proyecto de túnel bajo la ría de Bilbao, entre Lamiaco y Sestao

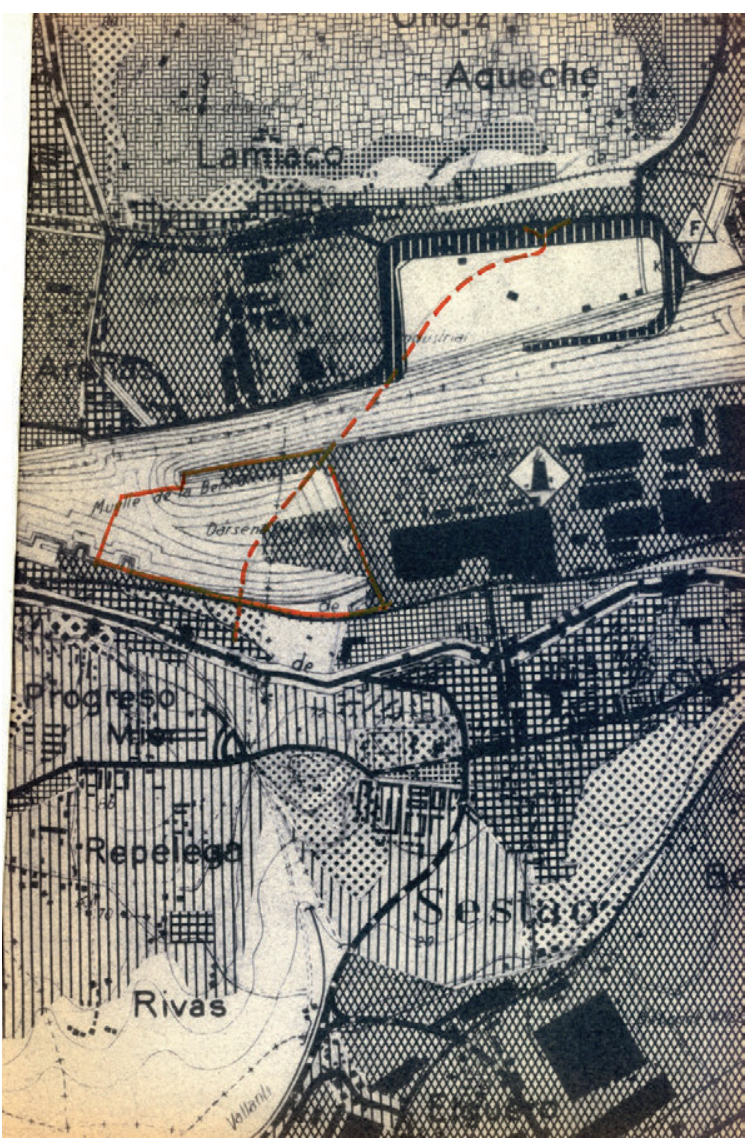

Fuente: Archivo Foral de Bizkaia, Sección Administrativo, Fondo Urbanismo, Signatura J-03058.

aquella reproductividad de lo americano una brusca mutación en la arquitectura decimonónica bilbaína, además de un abandono de la arquitectura local a su suerte, lo que conduciría a una segura desnaturalización de la ciudad. Porque, tal y como sustentaron los miembros del jurado que concedía el premio del COAVN Bizkaia, Pedro de Asúa, entre los que estaba Rafael Moneo, llegaron a argumentar que la americanización de la ciudad suscitó también una postura capitalista de beneficios como única meta, que trajo además de la anulación del hombre el que se culpabilizara a los arquitectos de no ser más que unos fríos técnicos y economistas. (Fig. 10).

\section{EPILOGO}

Si de extraordinaria hemos tachado la influencia que tuvo el pensamiento norteamericano -teniendo en cuenta que los Estados Unidos eran contemplados en el imaginario español como sinónimo de riqueza, prag- 
Figura 10. Proyecto de rascacielos en Deusto. Javier Sada de Quinto

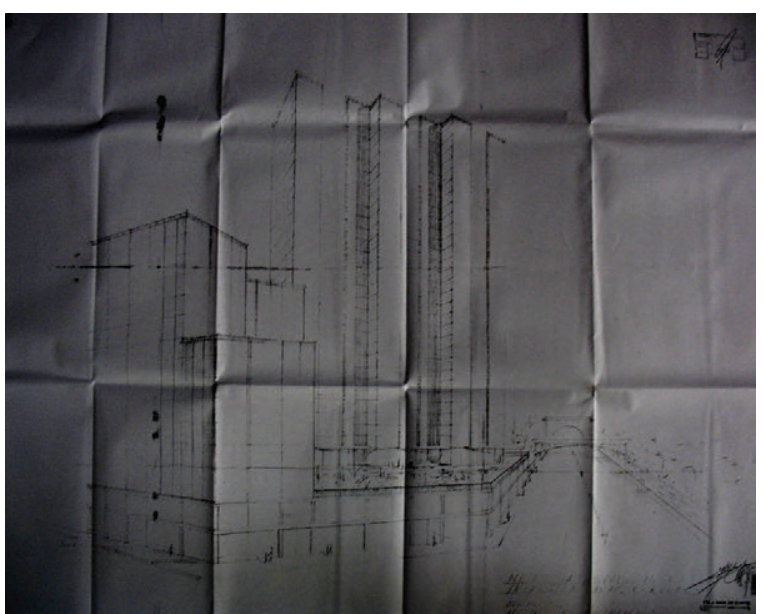

Fuente: Archivo General de la Administración Pública de la Comunidad Autónoma de Euskadi.

matismo, progreso científico-tecnológico y modernidad- sobre aquella España bajo la dictadura del general Franco -que representaba todo lo contrario-, más sorprendente aún lo fue, la que adquirió sobre la ciudad de Bilbao. Esta fue posible, tal y como hemos podido constatar, a través de una serie de instrumentos culturizadores: además de los viajes de los técnicos, científicos, empresarios y políticos bilbaínos a los EE.UU., la influencia que ejerció la Casa Americana en Bilbao, las memorias de quienes viajaron a los Estados Unidos, así como por medio de las campañas y series publicadas por la prensa escrita y la línea científica seguida por las revistas. Coincidían todos en un mismo propósito: la necesidad de modernizar Bilbao. Si la revolución tecnológica que llegaba desde los Estados Unidos, era la que proporcionaba aquel nivel de vida tan alto y le llevó a ser a ese país la primera potencia del mundo, era algo que seducía enormemente a los dirigentes bilbaínos, por lo que propusieron llevar a efecto una política tecnológica a imitación de la norteamericana, con sus modernos laboratorios y centros de investigación que habían revolucionado el futuro tecnológico, inundando el mercado mundial con sus más innovadores productos, sistemas y materiales, gracias a la eficiencia, a la iniciativa propia y a la simplicidad netamente norteamericana. Convendría destacar que aquel país, no solo causaba fascinación, sino que acto seguido seducía, para posteriormente acabar persuadiendo a políticos, técnicos e industriales bilbaínos de la necesidad de reproducir algunos de aquellos símbolos.

La pretensión de los dirigentes y empresarios bilbaínos de hacer de Bilbao no solo la gran metrópoli del norte sino que también la capital financiera e industrial de aquella España, a priori, pudo parecernos de una desmedida ambición, pero que vistos los objetivos económicos y de modernización de la ciudad que se vislumbraban por parte de los dirigentes locales, este anhelo y a la vez reivindicación, para ellos estaba más que justificada. Porque para llevar a cabo dicha pretensión trataron de reproducir no solo conceptos e ideales - un cambio de mentalidad- sino que también una transformación desde la praxis con los símbolos, hitos e iconos, -arquitectónicos o ingenieriles- propiamente norteamericanos, que servirían no solo como pretexto para adquirir una anhelada modernidad y la imagen de ciudad de éxito -la idea de metrópoli del 2000-, sino que también para tratar de romper con un pasado y un presente que poco o nada tenía que ver con los anhelos sobre todo de tipo económico de aquella gran burguesía bilbaína. Aquella clase dirigente tenía como máxima, la necesidad de imitar a los Estados Unidos que era el espejo en donde querían verse reflejados, porque vivían bajo una dictadura, que curiosamente representaba ya para muchos el pasado, lo retrogrado y la atmosfera cultural irrespirable, frente a los EE.UU. que eran tomados como la luz, el progreso, la innovación y el futuro. Dichas ideas acabarían implementándose en el imaginario de muchos bilbaínos, como un acto más, a favor de aquel cambio de pensamiento y de la modernidad que traía implícita.

\section{NOTAS}

1. Consultar las memorias editadas por la Comisión Nacional de Productividad Industrial del Ministerio de Industria en las que aparecen los numerosos grupos de técnicos, industriales y científicos españoles que viajaron a los Estados Unidos durante los años 50.

2. Marías estuvo como profesor invitado en Harvard, Yale, Wellesley y en la Universidad de California.
3. Autores como Hispanus, Perico Chicote, Diego Hidalgo, Luisa Trigo, José María Bartolomé, Rafael Aiguabella, Tomas Ríos, Jose Maria Zumalacarregui, Herminio Puertas, José Méndez Herreras, Eduardo Vicente, Alfonso de la Peña, Fernando Vela, Eduardo Giménez Caballero, Ricardo Royo, Carlos Sainz Robles, Luis Calvo, Manuel García Pelayo, Francisco Casares,
José Méndez Herrera, Herminio Puertas o Walter Lippman escribieron sobre diferentes facetas de los Estados Unidos en la prensa española.

4. A finales de los años 50, Abraham Hopman, cónsul americano en Bilbao, como parte de la política de intercambio de los Estados Unidos con la España de Franco, propuso al alcalde de Pittsburgh, Joseph Barr, herma- 
nar ambas ciudades, dada su analogía urbana e industrial. El entonces alcalde de Bilbao, Lorenzo Hurtado de Saracho, apoyó tal pretensión. La delegación de la Cámara de Comercio Americana en Bilbao como siguiente paso pretendió establecer un comité en cada ciudad bajo la presidencia de su respectivo alcalde. Así se mantendrían continuas relaciones para organizar los intercambios de visitas, exposiciones recíprocas, la publicación de reportajes en los diarios de ambas localidades, así como el intercambio de obsequios. Esperaban que surgieran beneficiosas derivaciones culturales y económicas que darían lugar a empresas comunes.

5. Luis Hernández Franch dictó en Bilbao una conferencia organizada por la Casa Americana con el título Rasgos que definen a un pueblo, dado que él era un periodista culto que había leído mucho sobre los Estados Unidos, había viajado a aquel país y conocido in situ su realidad (Hernández Franch, 1962). Hernández Franch fue total-

\section{BIBLIOGRAFÍA}

Aguinaga, P. L. (2009). Los canales de difusión del mensaje norteamericano en España, 1945-1960. En Niño, A. (ed.). La ofensiva cultural norteamericana durante la guerra fría. Ayer, 75, pp. 134-158. Disponible en: https:// www.ahistcon.org/PDF/numeros/ Ayer75_2009.pdf

Anónimo. (1953, 2 de febrero). Los Estados Unidos preparan hoy las revolucionarias técnicas del mañana. Dyna, p. 103.

Anónimo. (1954, 24 febrero). Bilbao es para Dunn el Pittsburgo de España. Pueblo.

Anónimo. (1955) El arte moderno en los Estados Unidos. Barcelona: III Exposición Bienal Hispanoamericana de Arte. pp. 25-74.

Anónimo. (1955, 4 de junio). Galerías Biosca exposición de Lois Langhorst. $A B C$.

Anónimo. (1957, 25 de abril). Los arquitectos españoles en los Estados Unidos. Los viajes de estudio en el plan americano de ayuda al exterior. El Correo Español/El Pueblo Vasco, p.12.

Anónimo. (1957). Viaje de estudios a Estados Unidos. Revista Nacional de Arquitectura, 184, pp. 37-40. mente favorable a tomar los ideales americanos como modelo a seguir por ser una sociedad de signo abierto.

6. Mónica Cruz planteaba esas ideas sobre los catálogos norteamericanos en el imaginario del progreso y su incidencia en la España del Desarrollismo.

7. La incidencia de los viajes en los ideales de los arquitectos españoles o la pretensión de manhattanizar ciudades como Madrid puede verse en Diez Medina (2006) o en Prieto (2006).

8. Las empresas americanas mantenían en su seno laboratorios y equipos de investigadores como el único procedimiento eficaz para no sucumbir ante las evoluciones de la competencia, mejorar en calidad sus productos, resolver cuestiones fundamentales en fabricación, modificar tipos, mantener la producción constante viva y la técnica siempre al día. En EE.UU. el número de centros de investigación era cuantitativamente mayor que en Europa con diferencia. Gracias a su política federal los centros se multi-

Anónimo. (1959) Formación de los científicos de la investigación en los Estados Unidos. Madrid.

Anónimo (1960, 8 de mayo). Se ha constituido en Bilbao la Asociación Cultural Hispano Norteamericana. La Vanguardia Española

Anónimo. (1961, 14 de diciembre). Conferencia en la Casa Americana de Félix Iñiguez de Onzoño. La Gaceta del Norte.

Anónimo. (1963, 22 de diciembre). Han regresado de Nueva York los arquitectos que han de construir el nuevo Banco de Vizcaya. El Correo Español/El Pueblo Vasco.

Anónimo. (1966, 2 de julio). EE.UU. prepara la ciudad del siglo XXI. Hierro.

Anónimo. (1971, agosto). Vivienda y centro comercial Bilbao grupo residencial Zabalburu. Arquitectura 152.

Assia, A. (1951, 26 de enero). La vida antes que la sabiduría, objeto principal en la universidad americana. El Correo Español/El Pueblo Vasco.

AA.VV. (1958). Memoria de Proyectos de viviendas y urbanización en EE.UU. Madrid: Comisión Nacional de Productividad Industrial. plicaban y los éxitos se sucedían sin interrupción e invadían los mercados internacionales de materiales y productos. El ingeniero Eduardo Torroja sostenía la necesidad de captar ideas y métodos, no hacer una mera copia de esas experiencias porque tendría para España consecuencias desastrosas (Torroja, 1951).

9. Frederic Langhorst acabó la carrera de arquitecto en la Cornell University en 1930. No solo se trataba de uno de los más brillantes discípulos de Frank Lloyd Wright (1932-1935), además fue socio junto a su mujer, Lois, del estudio Langhorst\&Langhorst en San Francisco entre 1942 y 1955. En 1949 le fue concedido el premio de honor del Instituto de Arquitectos Americanos, posteriormente en Europa fue nombrado director de la firma Daniel Mann, Johnson and Mendenhall y también fue nombrado arquitecto jefe del cuerpo de Ingenieros de la Armada Americana en Livorno y en España arquitecto director de la Architects Engineering Spanish Basiers.

Balda, F. J. (1970, 14 de abril). Fue fallado desierto el premio de arquitectura Pedro de Asúa, Hierro.

Barcelo, J. L. (1950, 29 noviembre). Mi viaje a los Estados Unidos. En el corazón industrial de los EE.UU. El Correo Español/ El Pueblo Vasco.

Bilbao, L. (2006). El debate en torno a la influencia de la arquitectura estadounidense en España: los arquitectos Luis Vázquez de Castro, Valentín Picatoste y las memorias de los técnicos españoles en EE.UU. En AA.VV. Actas del Congreso Internacional La arquitectura norteamericana, motor y espejo de la arquitectura española en el arranque de la modernidad (1940-1965) Pamplona: Escuela Técnica Superior de Arquitectura Universidad de Navarra, pp. 81-86. Disponible en: http://www.unav.edu/documents/29070/6431631/actas-05.pdf

Calle Iturrino, E. (1955). Del Nervión al Hudson. Crónicas del viaje a Cuba y a Estados Unidos a bordo del "Guadalupe". Bilbao: El Noticiero Bilbaíno.

Calvo, L. (1949, 11 febrero). Descubrimiento de Norteamérica. Visión de Nueva York. Pueblo, p. 12. 
Cassinello, P. (2013). Eduardo Torroja, think different. En Cassinello, P., Azorín, V., Sorli, A., Cassinello, N. y Foster, N. Eduardo Torroja 1949. Strategy to industrialise housing en post-world war II. Madrid: Fundación Eduardo Torroja/ Fundación Juanelo Turriano, pp. 19-38.

Cruz, M. (2006). Do it yourself: los catálogos en el imaginario del progreso. En AA.VV. Actas del Congreso Internacional La arquitectura norteamericana, motor y espejo de la arquitectura española en el arranque de la modernidad (1940-1965) Pamplona: Escuela Técnica Superior de Arquitectura Universidad de Navarra, pp. 97-98. Disponible en: http://www. unav.edu/documents/29070/6431631/ actas-05.pdf

Chueca Goitia, F. (1953). Experiencias arquitectónicas de un viaje a Norteamérica. Revista Nacional de Arquitectura, 135, pp. 39-50.

Delgado Gómez-Escalonilla, L. (2009). La maquinaria de persuasión. Política informativa y cultural de los Estados Unidos hacia España. En Niño, A. (ed.). La ofensiva cultural norteamericana durante la guerra fría. Ayer, 75, pp. 97-132. Disponible en: https://www.ahistcon.org/ PDF/numeros/Ayer75_2009.pdf

Diez Medina, C. (2006). Tras las huellas de América en España: un breve rastreo. En AA.VV. Actas del Congreso Internacional La arquitectura norteamericana, motor y espejo de la arquitectura española en el arranque de la modernidad (1940-1965) Pamplona: Escuela Técnica Superior de Arquitectura Universidad de Navarra, pp. 111-122. Disponible en: http://www.unav.edu/documents/29070/6431631/actas-05.pdf

Echevarria, A. (1949, 12 de febrero). Nueva York hoy: los rascacielos. Informaciones, p. 3.

Echevarria, A. (1965). El viaje a los Estados Unidos del alcalde de Guernica. Vizcaya, 25.

Ferrándiz Casares, J. (1957). Panorámica de los Estados Unidos. Atlántico, 7, p. 67.

García Millan, J. (2003). La arquitectura americana en España. En Sambricio, C. Un siglo de vivienda social (1903-2003) (vol. II). Madrid: Nerea, pp. 155-157.

Hernández Franch, L. (1950, 22 diciembre). Instantáneas de Norteamérica. Tipo único en los Estados Unidos. El Correo Español/El Pueblo Vasco, p. 5.
Hernández Franch, L. (1962). Rasgos que definen a un pueblo. Conferencia pronunciada en la Casa Americana de Bilbao. Madrid: Ediciones de Conferencias y Ensayos.

Iñigo, S. (1949, 2 de noviembre). Una visión inédita de Nueva York. Arriba, p. 3.

Langhorst, F. L. (1953). Método de la organización y contratación seguido por los Estados Unidos en las obras en Europa. Informes de la Construcción, 55, pp. 710-711.

Lucientes, F. (1948, 31 de diciembre). Los Estados Unidos hoy. El Correo Español/ El Pueblo Vasco.

Lleo, B. (2003) La moderna posguerra, 1949-1960 En Sambricio, C. Un siglo de vivienda social (1903-2003) (vol. II). Madrid: Nerea, pp. 22-23.

Marañón, G. (1961) Nueva York ida y vuelta. (Los Estados Unidos vistos por un español) Madrid: Ediciones de Conferencias y Ensayos, pp. 12-19.

Marías, J. (1956). Reflexiones sobre los Estados Unidos. Atlántico, 1, pp. 7-22.

Marías, J. (1972). Los Estados Unidos en escorzo. Madrid: Revista de Occidente.

Morales, J., de Giles, S. y González, J. (2004). Carlos Pfeiffer, entrevista. Los brillantes 50. 35 proyectos. Pamplona, T6 Ediciones. p. 296.

Moya, L. (1950). Frank Lloyd Wrigth. Revista Nacional de Arquitectura, 99, pp. 103-108.

Moya, L. (1950). Tradicionales, funcionalistas y otros. Revista Nacional de Arquitectura, 102, p. 269.

Neville, E. (1964, 9 de diciembre). Ay mi Madrid. $A B C$, p. 14.

Prieto M. (2006). Contenidos con efectos: arquitectura audiovisual de AZCA. En AA.VV. Actas del Congreso Internacional La arquitectura norteamericana, motor y espejo de la arquitectura española en el arranque de la modernidad (1940-1965) Pamplona: Escuela Técnica Superior de Arquitectura Universidad de Navarra, pp. 81-86. Disponible en: http://www.unav.edu/documents/29070/6431631/actas-05.pdf

Rodríguez, C. (2006) Mr. Marshall viene a casa. La escenografía de la modernidad americana en el tiempo del desarrollismo español" En AA.VV. Actas del
Congreso Internacional La arquitectura norteamericana, motor y espejo de la arquitectura española en el arranque de la modernidad (1940-1965) Pamplona: Escuela Técnica Superior de Arquitectura Universidad de Navarra, pp. 205-216. Disponible en: http://www. unav.edu/documents/29070/6431631/ actas-05.pdf

Rodríguez Aranda, L. (1957). El espíritu del pragmatismo americano. Atlántico, 6. p. 38.

Romero, E. (1950, 2 de mayo). Autobuses y cafeterías americanas. Pueblo.

Romero, E. (1951, 23 de enero). Variaciones sobre el problema de la vivienda. Pueblo.

Sambricio, C. y Frechilla, J. M. (2014). Arquitectura española del exilio. Madrid: Lampreave.

Sambricio, C. (2004). Luis Laorga y las viviendas para los militares americanos. En Los brillantes 50, 35 proyectos, (pp. 198-213) Pamplona, T6 Ediciones.

Sambricio, C. (2004). Madrid, vivienda y urbanismo: 1900-1960. Madrid: Akal, pp. 406-407.

Torroja, E. (1951). Las actividades del Instituto de la Construcción y del Cemento. Informes de la Construcción, 27, pp. 71-73.

Van Doren, C. H. (1956) ¿Que es la cultura americana? Atlántico, 3, p. 36.

Wilhelmsen, F. D. (1960). El alma norteamericana. Madrid: Ateneo de Madrid, pp. 7-22

\section{Recursos de Internet}

Bilbao, L. Arquitectura norteamericana en Bilbao. [En línea]. Disponible en http:// www.bilbaopedia.info/

Bilbao, L. Bilbao y Pittsburgh: ciudades hermanas. [En línea]. Disponible en http:// www.bilbaopedia.info/

Bilbao, L. Casa Americana en Bilbao 19491961. [En línea]. Disponible en http:// www.bilbaopedia.info/

Bilbao, L. Eugenio Aguinaga: consecuencias de un viaje de estudio a los EE.UU. de un arquitecto bilbaíno. [En línea]. Disponible en http://www.bilbaopedia. info/ 